\title{
A Proposed Constructive Model and its Impact on Triple Jump Race Learning among Faeulty of Physieal Education Female Students at the University of Sadat City.
}

\author{
Eman Ibrahim El-Sisi \\ Department of Track and Field, Faculty of Physical Education, University of Sadat city, Egypt. \\ Noha M.El-Sawaf \\ Department of Track and Field, Faculty of Physical Education, University of Sadat city, Egypt.
}

\begin{abstract}
The current study aimed to design a program based on the constructive model and investigate its effect and its effect on learning undergraduate female students the triple jump race. Participants of the study included 40 female students, who were enrolled in the second year at the faculty of physical Education, university of Sadat city. They were divided into an experimental group $(N=20)$ and a control group $(N=20)$. The quasi-experimental experimental - control group, pre-post design. The experimental group received constructive learning whereas the control group received traditional learning through the practical performance model. The findings revealed that there are statistically significant differences between the mean of post evaluations of both groups on some physical variables and the skilful and numerical levels in favor of the experimental group's post-evaluation.
\end{abstract}

Key words: A proposed constructive model, trid jump race, learning..

\section{Introduction:}

$\mathrm{T}$ lechnology is penetrating all the various spheres of life including education. Therefore, it is import to prepare the teachers to cope with the rapid changes, in order to make use of the best available technology in enhancing the different methods, models, and techniques of teaching /learning instead of the traditional learning methods.

Al-Gendi and Monir (2001) pointed out that developing education requires that teachers should reconsider the ways in which pupils are thinking. What matters is not what pupils learn, but to learn how to think. And set the teacher free of the radical teaching methods.

Al Faleh (2003) pointed out that more attention was focused on experimenting a number of non-traditional methods of teaching and learning. Some of these methods were derived from the constructive theory.

Constructive learning moved from focusing on the external factors that include; such variables as teacher, school, and curriculum, to concentrating on the internal factors, which affect the learning process. This means to focus on what takes place in the learner's mind when he /she encounters a learning situation such as prior and background knowledge
Maximos (2003) mentioned that the students in the constructive learning model are helped to construct their knowledge according to four phases, which derived from the stages of learning cycle. The four phases of constructive learning include the inviting stage, the exploratory stage, proposing solutions and interpretations stage and the application stage

Al-Gendi (2003) stated that the teacher's role in constructive learning is not confined to transmitting knowledge but he acts as a guide in the process of constructing knowledge. The learner, then, constructs meaning out of the new information and the events resulting from the interaction between the individual's prior knowledge and experiences.

Triple jumping is one of the races that have several complex stages that require thorough understanding to join and perform them in a good manner. The review of literature and studies revealed that the constructive learning model offers several benefits and provides learners with opportunities to search for knowledge and information, analyses, interpret, connect and find the relationships among information. Accordingly, the researchers were encouraged to think of a constructive learning model and investigate its effect on triple jump race among Faculty of physical education female students at Sadat city university.

- Aims of the study 
The current study aimed at designing a program that bassed on constructive leaning model and investigate its effect on:

1. Some physical variables of the study participants.

2. The skill and personal record of the participant's triple jump race.

\section{-Hypotheses of the study}

1. There are statistically significant differences between the means of experimental group's pre-post evaluations on triple jumping through the constructive learning model in some physical variables and skilful and numerical levels in favor of post - administration

2. There are statistically significant differences between the means of control group's pre-post evaluations on triple jumping through the regular (conventional) learning in some physical variables and skilful and numerical levels in favor of postevaluations.

3. There are statistically significant differences between the means of the experimental and the control group's post administration in some physical variables and skilful and numerical levels in favor of the experimental group's post administration.

\section{-Method and procedures}

\section{Design of the study-}

The researchers used the quasi-experimental approach with the experimental - control group, pre-post design. The experimental group used the constructive learning model whereas the control group used traditional learning through the practical performance. The evaluation was according to the difference between groups' post measurements.

\section{-Participants of the study:}

The participants of the study included 40 female students at the second year, faculty of physical Education, Sadat City University. They divided into an experimental group $(\mathrm{N}=20)$ and a control group $(\mathrm{N}=20)$. In addition, 20 students participated in the pilot study.

-Pre- measurements:
The pre-measurements of both groups were to find the equivalent and homogeneous in age, height, weight, intelligence, and physical variables.

\section{-The educational program}

It based on the constructive learning model in purpose of teaching the participants the triple jump race

\section{-The content of the program}

A) Inviting stage:

In this stage, students were invited to learn and respond to the teacher's questions or pictures and problems that require thinking and search for solutions and answers to the questions related to their background knowledge.

B) Exploratory stage:

In this stage, the students explored the problem then, search for the answers and interpretations through observation, measurement, and experimentation. In addition, students were divided into small groups where each group took the experiment and be prepared for the discussion with the teacher.

C) Proposing interpretations and solutions stage:

In this stage, the teacher discussed the students in each group, they presented the solutions that they reached, then students misconceptions were corrected.

D) The application stage:

In this stage, students attempt to apply what they have reached to subsequent situations. It is important for teachers to give the students the opportunity to apply what they learned.

\section{-Post-measurements}

Post-measurements were performed on both the experimental and control groups to investigate the effect of the applied program on students' physical variables, skill level, and record of triple jumping. Post measurements took place on Saturday 26/4/2014 and Sunday 27/4/2014.

\section{- Results and discussion:}

\section{A) Results}

\section{First Hypothesis and its Discussion}


Table(1)

Means and Standard Deviation between pre and post measurements of the Experimental Group

\begin{tabular}{|c|c|c|c|c|c|c|}
\hline \multirow{2}{*}{ Variables } & \multirow{2}{*}{ Measuring unit } & \multicolumn{2}{|c|}{ Pre } & \multicolumn{2}{|c|}{ Post } & \multirow{2}{*}{ T $^{*}$} \\
\cline { 3 - 6 } & & M. & SD & M0 & SD & \\
\hline Flexibility & Frequency & 22.20 & 1.79 & 27.65 & 1.87 & 10.57 \\
\hline agility & Time & 16.49 & 0.95 & 14.37 & 0.93 & 8.69 \\
\hline Speed characteristic & Distance & 1.50 & 0.192 & 1.66 & 0.113 & 3.347 \\
\hline Transitional speed & Second & 7.35 & 1.182 & 4.78 & 0.451 & 8.600 \\
\hline Co-ordination & Frequency & 0.50 & 0.688 & 3.75 & 0.786 & 12.485 \\
\hline Personal Record & Distance & 0.62 & 0.573 & 6.38 & 0.641 & 37.987 \\
\hline Skill level & Degree & 0.70 & 0.657 & 9.05 & 0.945 & 32.851 \\
\hline
\end{tabular}

* "T" value at $(0.05)=(1.7)$

Table (1) reveals that calculated " $t$ " values are greater than tabulated " $t$ " value at $(0.05)$. This reflects the fact that there are statistically significant differences between the means of the pre and post measurements of the experimental group in physical variables and skill level and personal record in favor of post administration

Table (2)

Improvement percentages of the investigated variables of the experimental group

\begin{tabular}{|c|c|c|c|c|c|c|}
\hline \multirow{2}{*}{ Variables } & \multicolumn{2}{|c|}{ Pre measurements } & \multicolumn{2}{c|}{ Post measurements } & \multirow{2}{*}{ Difference } & $\begin{array}{c}\text { Improvement } \\
\text { percentage (\%) }\end{array}$ \\
\cline { 2 - 5 } & M. & SD & M. & SD & & 19.71 \\
\hline Flexibility & 22.20 & 1.79 & 27.65 & 1.87 & 5.45 & 14.75 \\
\hline agility & 16.49 & 0.95 & 14.37 & 0.93 & 2.12 & 9.63 \\
\hline Power & 1.50 & 0.192 & 1.66 & 0.113 & 0.16 & 53.76 \\
\hline Transitional speed & 7.35 & 1.182 & 4.78 & 0.451 & 2.57 & 86.66 \\
\hline Co-ordination & 0.50 & 0.688 & 3.75 & 0.786 & 3.25 & 90.28 \\
\hline Personal Record & 1.62 & 0.573 & 6.38 & 0.641 & 5.76 & 92.26 \\
\hline Skill level & 0.70 & 0.657 & 9.05 & 0.945 & 8.35 & \\
\hline
\end{tabular}

Table (2) reveals the improvement percentages in the investigated variables measurements of the experimental group.

Table (1) indicates that there are statistically significant differences between the pre and post measurements of the experimental group in physical variables (flexibility, agility, power, Co-ordination, transitional speed, personal record, and Skill level) as calculated "t" was more than the tabulated one. As well as, table ( 2 ) reveals that there is improvement in the investigated variables measurements of the same group, where the percentages of improvement were $19.71 \% 14.75 \%, 9.63 \%, 53.76 \%, 86.66 \%, 90.28 \%$, and $92.26 \%$, for flexibility, agility ,power, transitional speed, personal record and skill level respectively.

According to the authors, such results were due to the constructive learning program. This program considered the student as the core of educational process. It required students to think and make use of background knowledge and experience in understanding the triple jump (technical phases and performance), thereby achieving such development and progress.

In this respect, sweilam and Radwan (2001) confirmed that the constructive learning model represents the students as the core of the learning process. They search for information, experiment, explore, and are engaged in discussion with peers and with the teacher. This involves them to participate actively, communicate better, and cooperate.

Zayton (2003) added that constructive learning is one of the methods that help students construct their knowledge ( concepts, principles and laws) about the new lesson through putting them in a problematic situation, helping them to conduct exploratory activities to test their 
preliminary ideas and then present their findings and interpretations to be used in new subsequent situations.

Bakkar and Al-Bassam (2004) emphasis that the constructive learning enables learners to construct new ideas through their prior experiences and their cognitive structure, where the experiences interact with the new ones, in order to interpreting the surrounding situation.

Al-Mehi (2003) that the nature of the constructive learning program contains various instructional materials which are interesting, motivating and stimulating to students' mental

Table (3)

Means and Standard Deviation between pre and post measurements of the control group

\begin{tabular}{|c|c|c|c|c|c|c|}
\hline \multirow{2}{*}{ Variables } & \multirow{2}{*}{ Measuring unit } & \multicolumn{2}{|c|}{ Pre } & \multicolumn{2}{|c|}{ Post } & \multirow{2}{*}{$\mathrm{T}^{*}$} \\
\hline & & M. & $\mathrm{SD}$ & $\mathrm{M}$ & SD & \\
\hline Flexibility & Frequency & 21.35 & 2.60 & 24.00 & 2.64 & 5.55 \\
\hline agility & Time & 16.54 & 0.92 & 15.83 & 0.89 & 7.18 \\
\hline Power & Distance & 1.445 & 0.206 & 1.318 & 0.093 & 2.716 \\
\hline Transitional speed & Second & 7.526 & 1.140 & 5.957 & 0.330 & 6.693 \\
\hline Co-ordination & Frequency & 0.50 & 0.513 & 2.30 & 0.657 & 13.007 \\
\hline Personal Record & Distance & 0.59 & 0.802 & 4.65 & 0.639 & 15.907 \\
\hline Skill level & Degree & 0.75 & 0.716 & 6.90 & 1.021 & 19.309 \\
\hline
\end{tabular}

* "T" value at $0.05=(1.72)$

Table (3) reveals that calculated " $t$ " values are greater than tabulated " $t$ " value at (0.05). This reflects the fact that there are statistically significant differences between the means of the pre and post measurements of the control group in physical variables in favor of post measurements.

Table (4)

Improvement percentages of the investigated variables of the control group

\begin{tabular}{|c|c|c|c|c|c|c|}
\hline \multirow{2}{*}{ Variables } & \multicolumn{2}{|c|}{ Pre } & \multicolumn{2}{|c|}{ Post } & \multirow{2}{*}{ Difference } & \multirow{2}{*}{$\begin{array}{c}\text { Improvement } \\
\text { percentage }(\%)\end{array}$} \\
\hline & M. & $\mathrm{Sd}$ & M. & $\mathrm{Sd}$ & & \\
\hline Flexibility & 21.35 & 2.60 & 24.00 & 2.64 & 2.65 & 11.04 \\
\hline agility & 16.54 & 0.92 & 15.83 & 0.89 & 0.71 & 7.54 \\
\hline Power & 1.445 & 0.206 & 1.318 & 0.093 & 0.127 & 9.63 \\
\hline Transitional speed & 7.526 & 1.140 & 5.957 & 0.330 & 1.569 & 26.33 \\
\hline Co-ordination & 0.50 & 0.513 & 2.30 & 0.657 & 1.80 & 78.26 \\
\hline Personal Record & 0.59 & $0.8 \quad 02$ & 4.65 & 0.936 & 4.06 & 87.31 \\
\hline Skill level & 0.75 & 0.716 & 6.90 & 1.021 & 6.15 & 89.13 \\
\hline
\end{tabular}

Table (4) reveals the improvement percentages in the investigated variables measurements the control group. As the improvement percentages

were $11.04 \%, 7.54 \%, 9.63 \%, 26.33 \%, 78.26 \%, 87.31 \%$, and $89.13 \%$, for flexibility, agility, power, transitional speed, personal record and skill level respectively. and cognitive abilities. It also helps students construct their knowledge by themselves though the various stages of constructive learning. This resulted in retaining knowledge and information for long time and increasing students' level of achievement.

Al-Akeli (2005) added that constructive teaching considers students as active learners and the teacher as a coach and a leader of learning processes.

\section{-Second hypothesis and its Discussion}


having no background about the race is a vital reason of increasing the students`cognition

In addition, the conventional method is not costly and easy to use in the various stages. As well as, it can be used in over-crowded classrooms.
Ibrahim (2002) pointed out that the conventional method helps learners to receive information, avoid making mistakes, and receive the right answers (if they make mistakes) from the teacher.

\section{-Third hypothesis and its Discussion}

Table (5)

Means and standard Deviation of post measurements of the control and the experimental groups

\begin{tabular}{|c|c|c|c|c|c|c|}
\hline \multirow{2}{*}{ Variables } & \multirow{2}{*}{ Measuring unit } & \multicolumn{2}{|c|}{ experimental } & \multicolumn{2}{|c|}{ control } & \multirow{2}{*}{ "t"* } \\
\hline & & M. & $\mathrm{Sd}$ & $\mathrm{M}$ & $\mathrm{Sd}$ & \\
\hline Flexibility & Frequency & 27.65 & 1.87 & 24.00 & 2.64 & 3.087 \\
\hline agility & Time & 14.37 & 0.93 & 15.83 & 0.89 & 4.531 \\
\hline Power & Distance & 1.66 & 0.113 & 1.32 & 0.094 & 9.078 \\
\hline Transitional speed & Time & 4.780 & 0.451 & 5.957 & 0.320 & 10.832 \\
\hline Co-ordination & Frequency & 3.75 & 0.786 & 2.30 & 0.657 & 5.900 \\
\hline Personal Record & Distance & 6.39 & 0.641 & 4.65 & 0.639 & 14.439 \\
\hline Skill level & Degree & 9.05 & 0.945 & 6.90 & 1.021 & 6.015 \\
\hline
\end{tabular}

* "T" value at $(0.05)=(1.72)$

Table (5) reveals that calculated " $t$ " values are greater than tabulated " $t$ " value at (0.05). This reflects the fact that there are statistically significant differences between the experimental and the control groups' post measurements in physical variables and numerical and skill in favor of the experimental group's post-administration.

Table (6)

improvement percentages of the investigated variables' post measurements of the experimental and the control groups

\begin{tabular}{|c|c|c|c|c|c|c|}
\hline \multirow{2}{*}{ Variables } & \multicolumn{2}{|c|}{ experimental } & \multicolumn{2}{|c|}{ control } & \multirow{2}{*}{ Difference } & \multirow{2}{*}{$\begin{array}{c}\text { Improvement } \\
\text { percentage }(\%)\end{array}$} \\
\hline & M. & $\mathrm{Sd}$ & M. & $\mathrm{Sd}$ & & \\
\hline Flexibility & 27.65 & 1.87 & 24.00 & 2.64 & 3.065 & 15.20 \\
\hline agility & 14.37 & 0.93 & 15.83 & 0.89 & 1.46 & 9.22 \\
\hline Power & 1.66 & 0.113 & 1.32 & 0.094 & 0.34 & 25.75 \\
\hline Transitional speed & 4.780 & 0.451 & 5.957 & 0.320 & 1.177 & 19.75 \\
\hline Co-ordination & 3.75 & 0.786 & 2.30 & 0.657 & 1.45 & 63.04 \\
\hline Personal Record & 6.39 & 0.641 & 4.65 & 0.639 & 1.74 & 37.41 \\
\hline Skill level & 9.05 & 0.945 & 6.90 & 1.021 & 2.15 & 31.15 \\
\hline
\end{tabular}

Table (6) reveals the improvement percentages of the investigated variables' post measurements of the experimental and the control groups.

Table ( 5 ) indicates that there are statistically significant differences between two post-measurements of the two groups (experimental and control) in the physical variables, the personal record and the skill level in favor of the experimental group, as the value of calculated " $t$ " was greater than the tabulated " $\mathrm{t}$ "

Table (6) indicates that the improvement percentages of the post measurements of the experimental and the control groups in the investigated variables were $15.20 \%$, $9.22 \%, 25.75 \%, 19.75,63.04 \%, 37.41 \%$ and $31.15 \%$ for flexibility ,agility, power, transitional speed, coordination, personal record and skill level respectively.

Such results, according to the outhres, are due to using the constructive learning model. Unlike the experimental group, the control group students remained passive, receiving information only and responding to the teacher. Rarely do they initiate and completely depend on the teacher's lecturing 
Aziz (2002) pointed out that the problem in conventional learning lies in emphasizing the subject - matter and the information conveyed to students neglecting the learners' participation in the learning process.

Farag (2005) added that, in the conventional learning, there are many disadvantages. The classrooms are crowded and the qualified teachers are few. Most of them do not pay more attention to individual differences. They focus on lecturing and providing much information to which students do not cope with

Unlike conventional learning, the constructive learning model has several advantages. It motivates and stimulates students to seek for the knowledge and collecting information in each of the race's stages. This is reflected in the experimental group's improvement and progress in the physical variables as well as personal record and skill level

This is consistent with $\mathrm{Al}-\operatorname{Agamy}(2003)$ who pointed out that the learner, in the constructive learning model, is the core of the learning process, He / She deals with the problem, collects the information that might help in solving the problem, discusses such solutions and, then attempts to apply them in a scientific manner

Al-kilany (2001) adds that when students, in constructive learning, find out the scientific concept and write it in a scientific manner; they can connect it with other concepts and apply it. This increases the understanding of such a concept and retaining it longer

This is also confirmed by Zaitoun (2003), He pointed out that the learner, in constructive learning, is more active in acting the role of the scientist who searches for the appropriate solutions to the problems encountered. The learner, then, is the core of learning and performs an active role in the learning process.

\section{Conclusions.}

1. there are statistically significant differences between the pre and post measurements of the experimental group in physical variables, personal record and skill level in favor of post measurements.

2. There statistically significant differences between the pre and post measurements of the control group in some physical variables personal record and skill level in favor of post-administration.

3. There are statistically significant differences between two post-measurements of the two groups (experimental and control) in the physical variables, the personal record and the skill level in favor of the experimental group

\section{Recommendations}

1- Using the proposed constructive model in teaching the triple jump race to undergraduate students.

2- Teaching other track and field races using the constructive model.

3- Using the constructive model in teaching track and field races in the various stages of education.

\section{References.}

1. Al-Agamy, L.(2003) the effectiveness of constructive and cognitive models in developing school achievement modifying alternative conceptions, basic science processes and attitude toward science among 2 nd year

2. Al-Akeli ,A.(2005) Theoretical and Applied Applications of Arabic language teachers in Riyadh and its relationship with constructive theory, Educational journal, Kuwait ,Faculty of Education, Kuwait university , vol.19,No.76,P.260.

3. Al-Fateh,S.k.(2003) The effectiveness of the realistic model in developing school achievement, science processes, modifying misunderstanding and attitude towards science among first intermediate school female students (girls) in Riyadh, scientific Education Journal, Egyptian society for scientific education Faculty of Education Aim shams University, Cairo , Vol.6,No.1,P.58

4. Al.Gendy, A. (2003) the effect of using whitly model on developing 5th primary pupils' achievement, skills of basic Education processes and scientific thinking. Egyptian society for scientific Education, Faculty of Education ,Ain Shams University, Cairo, volume(6), , No.(1), P.3.

5. Al-Gendy, A. and Monir, A.(2001) The effectiveness of using meta-cognitive strategies in science achievement and the development of creative thinking among 3rd preparatory school pupils with various mental capacities, 5th 
scientific symposium volume one, Egyptian one , Egyptian society for scientific for scientific Education, Ain Shams University, Cairo , P.363.

6. Al-kilany, F-(2001) the effect of modified learning cycle on science achievement for first year secondary (scientific section) female students. Unpublished M.Ed Thesis, Faculty of Education, Al-Yarmook University, Jordan

7. Al-Mehi, R. (2003). The effect of varying the type of practising instructional activities in a proposed model of teaching based on technological advances and constructive theory on achievement and developing picture reading skills and creative thinking in science among secondary stage students scientific education Journal, Egyptian society for scientific Educaion Faculty of Education, Ain Shams University, Cairo, Vol.6, No.3, P.27.

8. Aziz, M. (2002) Effective Teaching: definition, skills and management, Al Anglo Egyptian Publishing House Cairo, P.396.

9. Bakkor, N.and Al-Bassam (2004): Teachers as developers for textbooks content, a study of the status -quo and development from the constructivists, perspective, Arab Gulf Mission, Arab Gulf Education office, Riyadh, P.13.

10. Barhoom, A.M. (2013). The effect of using blended learning in developing the concepts and skills of using the technological advances incorporated in "technology of Education" course among female students in faculty of education. M.A.dissertation Faculty of Education, Gazza

11. Farag, A. (2005): Employing Internet in Education and curricula Educational Journal, vol.19,No.74,P.121

12. Hammam, A.and Soliman, k. (2001). The effect of using the constructive learning model in teaching science on developing some scientific concepts and critical thinking among second year preparatory pupils, Faculty of Education journal, Faculty of Education, Minia University ,vol.15, No.2,p.108.

13. Maximous, w. (2003). Constructivism in Mathematics teaching and learning, 3rd Arab symposium: systemic Approach in teaching and learning, Ain Shams University, Cairo, P.55.

14. Zaitoun, k. (2003) Designing instruction: A constructive perspective, studies in curriculum and Instruction, Egyptian society for curriculum and instruction, faculty of education, Ain Shams university ,Cairo ,No.91,P.383

15. Zaitoun, H. (2003). Teaching strategies: A contemporary view for methods of teaching and learning, 1st edition Aalam El Kotob publishing House, Cairo. 
